\title{
Evidence for monoclonal T lymphocyte proliferation in angioimmunoblastic lymphadenopathy
}

\author{
N T J O'CONNOR,* J A CRICK, ${ }^{*}$ J S WAINSCOAT, $\dagger$ K C GATTER, $\ddagger$ H STEIN,§ \\ B FALINI, $\|$ D Y MASON $\ddagger$
}

From the *Medical Research Council, Molecular Haematology Unit, the Departments of $\dagger$ Haematology and $\ddagger$ Pathology, University of Oxford, John Radcliffe Hospital, Oxford, the §Department of Histopathology, University of Berlin, West Germany, and the \|Department of Histopathology, Istituto di Clinica Medica Generale e Terapia Medica I, Università di Perugia, Italy

SUMMARY The arrangement of the $T$ cell receptor and immunoglobulin genes was analysed in lymphoid tissue biopsy specimens from 25 cases of angioimmunoblastic lymphadenopathy. Nineteen cases showed a rearrangement of the gene coding for the $\beta$ chain of the T cell receptor, and in one case a clonal rearrangement of immunoglobulin genes was shown (in which the $\mathrm{T}$ cell receptor gene was in a germline configuration). These findings indicate that a monoclonal $T$ cell proliferation is present in most cases of angioimmunoblastic lymphadenopathy, and they also correlate with the fact that some patients who present with this disorder subsequently develop a T cell lymphoma.

Angioimmunoblastic lymphadenopathy with dysproteinaemia (AILD) was described by several authors in the early 1970s. ${ }^{12}$ Patients usually have a short history of constitutional symptoms accompanied by generalised lymphadenopathy, and in many cases, by hepatosplenomegaly and skin rashes. Hypergammaglobulinaemia is often present and may be associated with autoimmune phenomena such as a Coombs positive haemolytic anaemia..$^{1-3}$ Lymph node biopsy specimens show a typical appearance, with normal tissue being effaced by a mixed cellular infiltrate, in which immunoblasts and plasma cells are prominent. This cellular infiltrate is accompanied by a striking "arborising" proliferation of blood vessels, and in many biopsy specimens, by an amorphous deposition of acidophilic material between the cells. ${ }^{124}$

AILD is considered to be a benign disorder despite the fact that the median survival from diagnosis is less than two years. ${ }^{1-3}$ Most patients die from opportunistic infection associated with lymphocyte depletion, but the clinical course is very variable with about a third of patients achieving a remission either spontaneously or following steroid or cytotoxic drug regimens, or both. ${ }^{134} \mathrm{~A}$ small group of patients, probably less than $10 \%$, progress to develop a frank lymphoma. ${ }^{13}$

Accepted for publication 27 May 1986
Although the clinical and histological features of this disorder are well defined, they provide no indication as to the underlying nature of the disease. In their original description of AILD the predominance of plasma cells and plasmacytoid lymphocytes in biopsy samples, together with the common finding of a polyclonal hypergammaglobulinaemia, led Lukes and Tindle to suggest that AILD was a hyperimmune proliferation of B cells. ${ }^{1}$ No causative agent responsible for this florid B cell reaction, however, has been identified, ${ }^{3}$ although Lukes and Tindle proposed that the disorder might result from a deficiency of $T$ cell regulatory function. ${ }^{1}$

Recent studies have shown that gene mapping with DNA probes specific for immunoglobulin (Ig) heavy and light chain genes may indicate the monoclonal B cell origin of a lymphoma. ${ }^{56}$ This relies on the fact that the genes which encode Ig chains undergo rearrangement during $B$ cell development. More recently, the gene for the $\beta$ chain of the T cell receptor has been cloned and shown to have a similar structure to that of Ig genes. ${ }^{7}$ Thus the demonstration of rearrangement of the $T$ cell receptor $\beta$ chain gene has been used to provide evidence for the monoclonality of $T$ cell leukaemias ${ }^{89}$ and lymphomas. ${ }^{1011}$

In this study we analysed DNA extracted from 25 cases of histologically typical AILD for evidence of clonal rearrangement of $\mathrm{Ig}$ and $\mathrm{T}$ cell receptor genes. The investigation showed the presence of a mono- 
clonal $\mathrm{T}$ cell proliferation in 19 of the 25 cases. These observations provide objective evidence that some cases of AILD are associated with a monoclonal T cell proliferation.

\section{Material and methods}

\section{SAM PLES}

Tissue samples from 25 cases of AILD were obtained from the histopathology department, John Radcliffe Hospital, Oxford, and the National Lymphoma Registry in Kiel, West Germany. Biopsy samples from each case were classified by examination of paraffin embedded tissue. They were also characterised immunohistologically by staining cryostat sections with panels of monoclonal antibodies as previously described. ${ }^{12}$ All cases showed the typical histological picture of AILD. In particular, any cases showing evidence of frank lymphoma were excluded from the study. Monoclonal antibody staining for $\mathrm{T}$ helper: $\mathrm{T}$ suppressor ratios was also undertaken on each sample.

\section{DNA ANALYSIS}

DNA was extracted from frozen biopsy specimens of 25 cases of AILD by routine methods and digested with restriction endonucleases. ${ }^{13}$ Control DNA was obtained from the peripheral blood of 36 healthy caucasian volunteers. The DNA fragments were subjected to electrophoresis in an $0.8 \%$ agarose gel and transferred to nitrocellulose filters by Southern blotting. Filters were hybridised with ${ }^{32} \mathrm{P}$ labelled probes specific for Ig and T cell receptor genes, washed under appropriate conditions, and subjected to autoradiography. ${ }^{13}$ The DNA probes were labelled by the method of oligonucleotide labelling. The four probes used in this study were an Ig heavy chain joining region $J_{H}$ probe (C76R51A: EcoRI fragment), an Ig $\kappa$ chain constant region $C_{k}$ probe (pUCR $17 C_{k}$ ), an $\operatorname{Ig} \lambda$ chain region $C_{\lambda}$ probe $(\mathrm{Chr} 22 \lambda 5),{ }^{14}$ and a $\mathrm{T}$ cell receptor $\beta$ chain probe (Jurkat $\beta 2$ : HindII $0.8 \mathrm{~kb}$ fragment against the constant region). ${ }^{7}$

Immunoglobulin genes All DNA samples were digested with BstI (an isoschizomer of BamHI), EcoRI and with HindIII before hybridisation with the $\mathbf{J}_{\mathbf{H}}$ probe. DNA was digested with BstI and BglII before $C_{k}$ hybridisation and Hind III and EcoRI before $C_{\lambda}$ probe hybridisation. All control samples showed identical restriction fragment patterns with the above enzymes and probes, no DNA polymorphisms or rearrangements being observed.

\section{$T$ cell receptor $\beta$ chain gene}

All DNA samples were digested with BstI, EcoRI, and Hind III before hybridisation with the T cell receptor $\beta$ chain gene probe. All control samples showed identical patterns with BstI EcoRI and with Hind III. ${ }^{10}$

A rearrangement was defined as having occurred if after digestion with a specific restriction endonuclease a new band was observed on autoradiography after hybridisation with the gene probe. Where possible rearrangements were shown with at least two enzymes (table) to exclude the possibility of abnormal bands being caused by DNA polymorphism.

\section{Results}

DNA from 19 of 25 AILD biopsy specimens showed clonal rearrangements of the T cell receptor $\beta$ chain genes while the Ig genes in these cases were all in a germline configuration. In 15 of the 19 cases rearrangement of the $T$ cell receptor $\beta$ chain gene was detectable after digestion with at least two enzymes. In four cases a rearrangement was detected after EcoRI digestion only, and in each case this finding was reproducible. These four rearrangements were different in size, and the band strength was well below that which would have been observed with a DNA polymorphism. This implies that a clonal $\mathrm{T}$ cell expansion was present in these 19 biopsy samples with no evidence of a clonal $\mathrm{B}$ cell disorder. One of the remaining six cases (with germline $\mathrm{T}$ cell receptor $\beta$ genes) showed a clonal rearrangement of both the $J_{H}$ and $C_{k}$ genes, giving objective evidence of a clonal $\mathrm{B}$ cell disorder. The five other cases gave normal patterns for both Ig genes and the T cell receptor $\beta$ gene-that is, they showed no evidence of either a B or T cell clone. The table summarises the results of DNA analysis with Ig gene and the T cell receptor $\beta$ chain gene probes for the 25 cases of AILD. In those cases with T cell receptor $\beta$ gene rearrangement there was no similarity (as judged by the size of the bands generated on autoradiography) between any two cases of AILD.

Genotypic classification of 25 cases of angioimmunoblastic lymphadenopathy

\begin{tabular}{|c|c|c|c|c|c|}
\hline \multicolumn{4}{|c|}{ Gene configuration } & \multirow{2}{*}{$\begin{array}{l}\text { No of } \\
\text { cases }\end{array}$} & \multirow[b]{2}{*}{ Conclusion } \\
\hline \multicolumn{4}{|c|}{ Gene studies } & & \\
\hline $\mathbf{J}_{\mathbf{H}}$ & $\mathrm{C}_{\mathrm{k}}$ & $\mathrm{C}_{\lambda}$ & TCR $\beta$ & & \\
\hline G & G & G & $\mathbf{R}$ & 19 & $\begin{array}{l}\text { Monoclonal T cell } \\
\text { expansion }\end{array}$ \\
\hline G & G & G & G & 6 & $\begin{array}{l}\text { No evidence of clonal } \\
\text { disorder }\end{array}$ \\
\hline $\mathbf{R}$ & $\mathbf{R}$ & G & G & 1 & $\begin{array}{l}\text { Monoclonal B cell } \\
\text { expansion }\end{array}$ \\
\hline
\end{tabular}

$\mathbf{R}=$ rearranged configuration shown after digestion with at least two enzymes, except for four cases in which the rearrangement was only seen after digestion with one enzyme.

$\mathbf{G}=$ germline configuration after digestion with all enzymes for each probe. 
When the cases were reviewed histologically there was no correlation between the morphological appearance of a biopsy sample and the presence or absence of a clonal $\mathrm{T}$ cell receptor $\beta$ gene rearrangement. There was also no association between the results of monoclonal antibody staining and the detection of a $\mathrm{T}$ cell clone.

Results of dilution experiments have shown that we can accurately show a clonal DNA rearrangement when it is present in less than $2.5 \%$ of a sample. As each gene possesses two alleles, and a specific Ig of $\mathrm{T}$ cell receptor $\beta$ rearrangement affects only one allele; this represents an ability to detect a clone of $5 \%$ cells in a specific biopsy.

\section{Discussion}

The results reported in this paper indicate that a monoclonal proliferation of $\mathrm{T}$ cells was detectable by DNA analysis in the lymphoid tissue of $76 \%$ of the cases of AILD studied. It should be emphasised that biopsy specimens in which there was histological evidence of lymphomatous change were excluded from the study, and it was only by application of gene rearrangement techniques that these monoclonal $T$ cell populations could be shown.

The finding of a clonal $\mathrm{T}$ cell proliferation in AILD has not been reported previously. It is noteworthy, however, that evidence for a $\mathrm{T}$ cell abnormality in AILD already exists, with reports of $T$ cell deficiency ${ }^{153}$ and anergy ${ }^{3}$ in patients with this disorder. Furthermore, in vitro studies of lymphocytes from patients with AILD have shown depressed T cell suppressor function. ${ }^{1617}$ It has also been emphasised that AILD may coexist with a malignant $T$ cell lymphoma; ${ }^{418}$ in a recent review of 42 cases of $T$ cell lymphoma $5 \%$ of the patients had a preceding diagnosis of AILD. ${ }^{19}$

Previous studies have shown that gene rearrangement analysis cannot accurately detect a monoclonal population of $\mathrm{B}$ or $\mathrm{T}$ cells when they account for less than $5 \%$ of the cells present in a tissue sample. ${ }^{5610}$ As the histological picture in AILD may be dominated by a polyclonal $\mathrm{B}$ cell proliferation the monoclonal $T$ cells shown in our study must have comprised only a minority cell population. It is hence possible that more sensitive methods might have shown a monoclonal $\mathrm{T}$ cell proliferation in all of the AILD samples studied.

One case showed a clonal rearrangement of both the heavy and light chain Ig genes (with the $T$ cell receptor $\beta$ genes in a germline configuration). The explanation of this single anomalous case is not clear at present, but it may indicate that AILD is occasionally caused by a clonal B cell expansion accompanied by a reactive $\mathrm{T}$ cell proliferation.
There are at least two hypotheses concerning the aetiology of AILD that would explain the results reported in the present study (fig 1). If a monoclonal proliferation of $\mathrm{T}$ cells is indeed present in all cases (although only detectable by current techniques in a proportion of samples) the pronounced polyclonal proliferation of $T$ and $B$ cells characteristic of this disorder may always be secondary to this underlying monoclonal population. An alternative hypothesis is that AILD is initially a polyclonal hypereactive disorder, affecting both $\mathrm{T}$ and $\mathrm{B}$ cells, and that $\mathrm{T}$ cell clones often arise as a secondary event.

At present it is not possible to decide which, if either, of these concepts is correct. The fact that spontaneous remission (unrelated to treatment) has been reported in a third of patients provides some argument against all cases being due to a clonal $T$ cell proliferation, although it is conceivable that the $T$ cell clone in these cases is of low neoplastic potential (comparable to a benign paraproteinaemia). Further studies using more sensitive methods for detecting a monoclonal lymphoid cell proliferation are needed to determine whether a clonal $\mathrm{T}$ cell proliferation is constantly present in AILD. Such an association would imply that a $\mathrm{T}$ cell clone is causal in the pathogenesis of AILD.

A prospective study of patients with AILD whose lymphoid tissue has been genotyped would also throw light on the importance of the finding of $T$ cell clones in this disorder. In those cases progressing to a $T$ cell lymphoma it would be interesting to determine

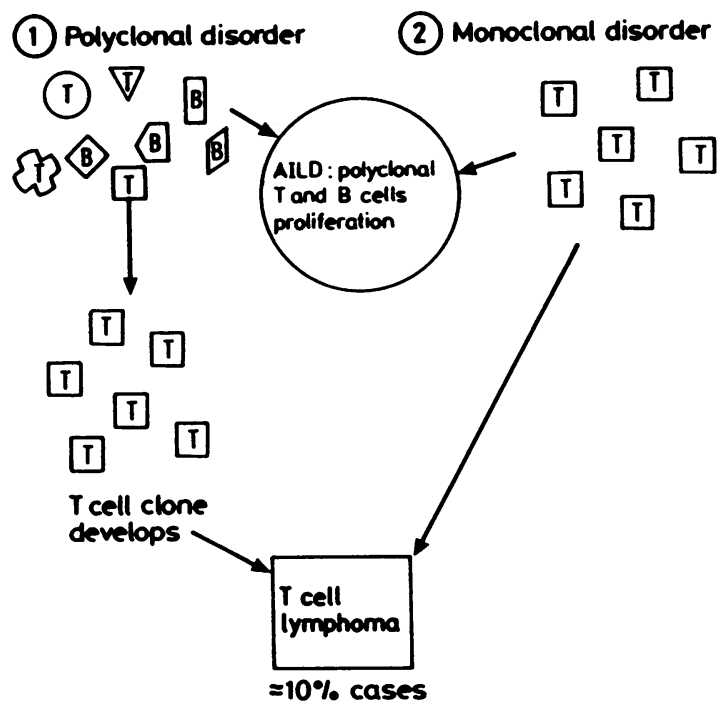

Figure Two alternative hypotheses to explain presence of clonal $T$ cell expansion in most cases of angioimmunoblastic lymphadenopathy. 
whether the lymphoma possesses the same or different patterns of $T$ cell receptor $\beta$ chain gene rearrangements as the original lymph node biopsy specimens. If the cases of AILD with monoclonal T cell proliferations evolve into $\mathrm{T}$ cell lymphomas with the same genetic rearrangement this technique may identify a group of patients who would benefit from cytotoxic chemotherapy.

We are very grateful to Professor K Lennert and Dr A C Feller from the Institute of Pathology, Kiel, West Germany, for generously providing us with lymph node biopsy specimens. We are also grateful to Professor DJ Weatherall for support and encouragement, to Dr Tak Mak for the T cell receptor Jurkat $\beta 2$ probe and to $\mathrm{Dr} \mathrm{T} \mathrm{H}$ Rabbitts for the Ig gene probes. NTJOC is in receipt of a Medical Research Council Training Fellowship. This work was also supported by grants from the Leukaemia Research Fund, the Wellcome Trust, and the Cancer Research Campaign.

\section{References}

1 Lukes RJ, Tindle BH. Immunoblastic lymphadenopathy: a hyperimmune entity resembling Hodgkin's disease. $N$ Engl $J$ Med 1975;292:1-8.

2 Frizzera G, Moran EM, Rappaport H. Angio-immunoblastic lymphadenopathy with dysproteinaemia. Lancet 1974;1: 1070-3.

3 Cullen MH, Stansfeld AG, Oliver RTD, Lister TA, Malpas JS. Angio-immunoblastic lymphadenopathy: report of ten cases and review of the literature. $Q J$ Med 1979;48:151-77.

4 Nathwani BN, Rappaport H, Moran EM, Pangalis G, Kim H. Malignant lymphoma arising in angio-immunoblastic lymphadenopathy. Cancer 1978;41:578-606.

5 Cleary ML, Chao J, Warnke R, Sklar J. Immunoglobulin gene rearrangement as a diagnostic criterion of B-cell lymphoma. Proc Natl Acad Sci USA 1984;81:593-7.

6 Arnold A, Cossman J, Bakshi A, Jaffe ES, Waldmann TA, Korsmeyer SJ. Immunoglobulin gene rearrangements as unique clonal markers in human lymphoid neoplasms. $N$ Engl J Med 1983;309:1593-9.
7 Yanagi Y, Yoshikai Y, Leggett K, Clark SP, Aleksander I, Mak TW. A human T cell-specific cDNA clone encodes a protein having extensive homology to immunoglobulin chains. Nature 1984;308:145-9.

8 Toyonaga B, Yanagi Y, Suciu-Foca N, Minden M, Mak TW. Rearrangements of T-cell receptor gene YT35 in human DNA from thymic leukaemia $\mathrm{T}$-cell lines and functional $\mathrm{T}$-cell clones. Nature 1984;311:385-7.

9 Minden MD, Toyonaga B, Ha Y, et al. Somatic rearrangement of $\mathrm{T}$-cell antigen receptor gene in human $\mathrm{T}$-cell malignancies. Proc Natl Acad Sci USA 1985;82:1224-8.

10 O'Connor NTJ, Wainscoat JS, Weatherall DJ, et al. Rearrangement of the $\mathrm{T}$-cell receptor $\beta$-chain gene in the diagnosis of lymphoproliferative disorders. Lancet 1985;i:1295-7.

11 Bertness V, Kirsch I, Hollis G, Johnson B, Bunn PA. T-cell receptor gene rearrangements as clinical markers of human T-cell lymphomas. $N$ Engl J Med 1985;313:534-8.

12 Stein H, Lennert K, Feller A, Mason DY. Immunohistological analysis of human lymphoma. Adv in Cancer Res 1984; 42:67-141.

13 Old JM, Higgs DR. Gene analysis. In: Weatherall DJ, Clegg J, eds. The thalassaemia syndromes. Oxford: Blackwell Scientific Publications, 1981:120-36.

14 Foroni L, Catovsky D, Rabbitts TH, Luzzatto L. DNA rearrangements of immunoglobulin genes correlate with phenotypic markers in B-cell malignancies. $\mathrm{Mol}$ Biol $\mathrm{Med}$ 1984;2:63-79.

15 Palutke M, Khilanani P, Weise R. Immunologic and electron microscopic characteristics of a case of immunoblastic lymphadenopathy. Am J Clin Pathol 1976;65:929-99.

16 Bluming AZ, Cohen HG, Saxon A. Angioimmunoblastic lymphadenopathy with dysproteinemia: a pathogenic link between physiologic lymphoid proliferation and malignant lymphoma. Am J Med 1979;67:421-8.

17 Skibin A, Yeremiyahu T, Keynan A, Quastel MR. Immunological studies in angioimmunoblastic lymphadenopathy Clin Exp Immunol 1980;39:386-94.

18 Neiman RS, Dervan P, Haudenschild C, Jaffe R. Angioimmunoblastic lymphadenopathy: an ultrastructural and immunologic study with review of the literature. Cancer 1978;41:507-18.

19 Greer JP, York JC, Cousar JB, et al. Peripheral T-cell lymphoma: a clinicopathologic study of 42 cases. J Clin Oncol 1984;2:788-96.

Requests for reprints to: Dr D Y Mason, Haematology Department, John Radcliffe Hospital, Headington, Oxford OX3 9DU, England. 